\title{
Endolymphatic Sac Surgery for Ménière's Disease - Current Opinion and Literature Review
}

\author{
Maria de Lourdes Flores García ${ }^{1}$ Carolina de la Llata Segura ${ }^{1}$ Juan Carlos Cisneros Lesser ${ }^{2}$ \\ Carlo Pane Pianese ${ }^{3}$
}

${ }^{1}$ Otorhinolaryngology Department, Grupo Otológico Médica Sur, México, DF, Mexico

2 Otorhinolaryngology and Neurotology Department, Instituto

Nacional de Rehabilitación, México, DF, Mexico

3 Otorhinolaryngology and Neurotology, Grupo Otológico Médica Sur, Neurociencias Clínicas e Investigación, Ciudad de México, DF, Mexico

\begin{abstract}
Address for correspondence Maria de Lourdes Flores García, MD, Puente de Piedra 150, 803-II, Toriello Guerra, Tlalpan, Ciudad de México, México (e-mail: mariluflogar@gmail.com).
\end{abstract}

\begin{abstract}
Keywords

- endolymphatic mastoid shunt

- endolymphatic sac decompression

- endolymphatic sac drainage

- endolymphatic sac surgery

- Ménière's disease.

Introduction The endolymphatic sac is thought to maintain the hydrostatic pressure and endolymph homeostasis for the inner ear, and its dysfunction may contribute to the pathophysiology of Ménière's disease. Throughout the years, different surgical procedures for intractable vertigo secondary to Ménière's disease have been described, and though many authors consider these procedures as effective, there are some who question its long-term efficacy and even those who think that vertigo control is achieved more due to a placebo effect than because of the procedure itself.

Objective To review the different surgical procedures performed in the endolymphatic sac for the treatment of Ménière's disease.

Data Sources PubMed, MD consult and Ovid-SP databases.

Data Synthesis We focus on describing the different surgical procedures performed in the endolymphatic sac, such as endolymphatic sac decompression, endolymphatic sac enhancement, endolymphatic sac shunting and endolymphatic duct blockage, their pitfalls and advantages, their results in vertigo control and the complication rates. The senior author also describes his experience after 30 years of performing endolymphatic sac surgery.

Conclusions The endolymphatic sac surgery, with all its variants, is a good option for patients with incapacitating endolymphatic hydrops, providing a high percentage of vertigo control and hearing preservation.
\end{abstract}

\section{Introduction}

The association of repeated attacks of vertigo that last for hours with a sense of aural fullness, fluctuating progressive hearing loss and tinnitus is characteristic of endolymphatic hydrops. In most cases, it is impossible to determine an etiology and a diagnosis of idiopathic endolymphatic hydrops, or Ménière's disease, until it is established. The endolymphatic sac is thought to maintain the hydrostatic pressure and endolymphatic homeostasis for the inner ear and its dysfunction is thought to contribute to the pathophysiology of Ménière's disease.

Vertigo attributed to endolymphatic hydrops, whether idiopathic or secondary to a known etiology, is amenable to either medical or surgical treatment. Treatment is usually symptomatic with sedatives and antiemetics during the acute phase, and diuretics or vasodilators for chronic control. Steroids are also useful either when applied directly with received

December 2, 2016

accepted

February 1, 2017
DOI http://dx.doi.org/

10.1055/s-0037-1599276. ISSN $1809-9777$.
Copyright $(2017$ by Thieme-Revinter

Publicações Ltda, Rio de Janeiro, Brazil
License terms

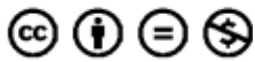


transtympanic injections or systemically. The psychological support of these patients is also an important part of the treatment. Surgical treatment is usually offered when the conservative therapy has failed and the vertigo becomes incapacitating and untreatable by other means. The surgical options include labyrinthectomy, vestibular neurectomy, endolymphatic sac surgery and transtympanic gentamicin injections for a chemical labyrinthectomy. ${ }^{1}$ However, the treatment options that appear to be most effective are those which are more invasive or that pose a greater risk for hearing loss. In this case, it is desirable to recommend a procedure that offers a high likelihood of vertigo control with maximum hearing preservation. ${ }^{2}$

Few surgical procedures in otology are as controversial as endolymphatic sac decompression. This surgical procedure offers the possibility of controlling vertigo with a minimal risk of morbidity by decreasing the amount of pressure in the endolymphatic space. A large number of authors think of it as safe and effective. The average success rate for vertigo control with this technique, considering different studies, is around $80 \% .^{3}$ Because of the low rates of hearing loss associated with this procedure, it is considered a conservative treatment. However, there are some who question its long-term efficacy, and even those who think that the vertigo control achieved after surgery is more due to a placebo effect than because of the procedure itself. ${ }^{4-6}$ Despite this controversy, many surgeons around the world still recommend the endolymphatic sac decompression.

\section{Review of the Literature}

The first surgical procedure for treating Ménière's disease was described in $1927^{7,8}$ by Portmann, who made a small incision to open the endolymphatic sac with the objective of decreasing the endolymphatic pressure. In 1938, Hallpike and Cairns ${ }^{9}$ demonstrated the pathological findings of endolymphatic hydrops in temporal bones taken postmortem from patients with long lasting Ménière's disease. Their findings in the inner ear, which suggested an augmented endolymphatic pressure that could provoke ischemia of the sensory terminal endings in the lateral walls of the membranous labyrinth, gave more credit to the surgical procedure described by Portmann. In 1962, William House ${ }^{10}$ described good results by performing a subarachnoid shunt to drain the endolymphatic hydrops. This renewed the interest in the technique, but it was not until 1967, when Kimura ${ }^{11}$ reliably reproduced an endolymphatic hydrops in guinea pigs by obliterating the endolymphatic duct and sac, that this type of surgery really caught the attention of a larger group of surgeons. Since then, various shunting techniques emerged, including subarachnoid shunts and mastoid shunts. In 1976, Paparella ${ }^{12}$ described a technique in which he emphasized the need of making a wide dural incision to expose and decompress the endolymphatic sac and duct completely, avoiding the posterior semicircular canal. Subsequently, open the sac and imporve its drainage via a T-tube that served as an endolymphatic duct valve. The results of this procedure in 75 patients were excellent, with control of vertigo in $94 \%$ of the patients, and even a significant improvement in cochlear function in $30 \%$ of them. Later, he called this surgical technique endolymphatic sac enhancement. ${ }^{13}$ Since then, others have described variations in the surgical technique for endolymphatic sac surgery with variable results. ${ }^{3,14}$

In 1981, Thomsen et $\mathrm{al}^{4}$ performed a double-blind study, in which they treated patients with Ménière's disease either with endolymphatic sac decompression and shunting, or with a simple mastoidectomy as a control procedure. They could not observe any difference between the two groups. However, a significant reduction in symptoms was reported in both groups, and $70 \%$ of all patients were classified as successfull considering the criteria used at that time. The study concluded that the surgical procedure had no effect whatsoever in the resolution of symptoms from Ménière's disease and that its efficacy was produced by a placebo effect. The patients were reexamined 3 years after surgery, and it was still not possible to demonstrate any differences between the sham and the active surgery. ${ }^{5} \mathrm{~A}$ few years later, in 1996, Södemann et al $^{15}$ suggested that the endolymphatic sac surgery was an excellent first choice in the treatment of uncontrollable vertigo because of its low complication rate, which, once again, shows how controversial this procedure really is. During the next year, other positive findings in favor of this procedure appeared; for instance, in 2005, Durland et $\mathrm{al}^{2}$ reported that this surgical procedure improves the perception of symptoms and the quality of life. In 2006, Convert et $\mathrm{al}^{16}$ reported a 10 -year follow-up of patients operated by endolymphatic sac decompression. They observed a resolution of vertigo episodes in $64.5 \%$ of their patients, with improved hearing in $14.8 \%$ of them. Goto et $\mathrm{al}^{17}$ and Kim et $\mathrm{al}^{18}$ reported similar results for vertigo control in recent years.

In a systematic review and meta-analysis from 2014 by Sood et al, ${ }^{19}$ current endolymphatic surgical techniques were analyzed, as well as their efficacy in controlling vertigo and maintaining hearing. This study demonstrated that both procedures, endolymphatic sac decompression alone or with a mastoid shunt, were effective to control vertigo in the short term (between 12 and 24 months of follow-up) and in the long term (> 24 months) in $75 \%$ of the patients with Ménière's disease who had no success with medical therapy. There was a trend towards sac decompression alone over shunting procedures to provide better vertigo control, as well as better hearing preservation, although this was not statistically significant. It was also noted that when shunting, there was a statistically significant difference in hearing preservation between shunting with and without Silastic (Dow Corning, Midland, Michigan, USA), against the use of Silastic.

It is known that Ménière's disease might have an immunological basis and that the endolymphatic sac itself may be the target of immunological complexes. This supports both the use of systemic or local steroids and that the endolymphatic sac is the obvious target of surgical procedures. In 1986, Brookes ${ }^{20}$ described the presence of high levels of circulating immune complexes in up to $54 \%$ of patients with 
Ménière's disease. Later on, Alleman et $\mathrm{al}^{21}$ tested the circulating immune complexes encountered in patients with Ménière's, exposing them directly to human endolymphatic sac tissue samples from 30 patients with Ménière's disease. These immune complexes reacted with the tissues of only $10 \%$ of the cases, suggesting that even if it is true that patients with Ménière's disease have high levels of circulating immune complexes, these may represent an external induction (viral, allergic or traumatic) more than an autoimmune phenomenon. Considering these and other studies that suggested that immune-mediated responses in the inner ear end organs, such as the endolymphatic sac and stria vascularis, could be the main reason for the development of symptoms in Ménière's disease, more and more studies involving the use of local or systemic steroids started to appear. This, in term, made reports of endolymphatic sac surgery less common. In 1997, Shea et $\mathrm{al}^{22}$ demonstrated that systemic and intratympanic combined administration of dexamethasone suppressed vertigo completely in $63.4 \%$ of the patients and improved hearing significantly in $35.4 \%$ of them 2 years after the treatment. Later on, in 2001, Sennarouglu et $\mathrm{al}^{23}$ reported that intratympanic perfusion of dexamethasone suppressed vertigo completely in $42.0 \%$ of patients and improved hearing significantly in $16.0 \%$ of them 2 years after treatment. In 2005, the senior author published his experience in a 2-year prospective, placebo controlled, double blind and randomized trial, with the use of dexamethasone inner ear perfusion by intratympanic injection in patients with unilateral Ménière's disease. Excellent results were observed and no complications or side effects were noted. The cost effectiveness of this officebased procedure was compared to that of endolymphatic sac decompression surgery, clearly in favor of dexamethasone perfusion. This procedure also offers other advantages over surgery, since it may be started immediately, even during acute episodes, being well tolerated and without the need of preoperative exams or evaluations. It may be used in hearing or non-hearing ears for patients whose systemic conditions are not amenable for a surgical intervention. ${ }^{24}$

In 2008, Kitahara et $\mathrm{al}^{25}$ suggested an interesting treatment modality that combined both procedures. These authors performed endolymphatic sac decompression with intra-endolymphatic sac application of steroids as a new therapeutic strategy for intractable Ménière's disease. They divided their patients in three groups, one in which only endolymphatic sac decompression was performed, another in which endolymphatic sac decompression was accompanied by intra-endolymphatic sac application of steroids, and another control group, which did none of the above. They found that the intra-endolymphatic sac application of large doses of steroids had additional effects to those of endolymphatic sac-expanding surgery, especially on hearing, and that both of the treated groups were superior to the non-surgical treatment of intractable Ménière's disease, both for vertigo control and hearing improvement for at least 7 years.

Another surgical procedure suggested to treat vertigo in patients with hard to control Ménière's disease is cochleosacculotomy, a surgical procedure performed through the round window to create a shunt between the cochlear duct and the saccule, with the objective of diminishing endolymphatic pressure. The problem with this procedure is that it damages hearing as well as vestibular functions. In different studies, its efficacy is compared to that of endolymphatic sac decompression. In 1991, Giddings et $\mathrm{al}^{26}$ performed this procedure and stated that the long-term control of vertigo was poor and, more importantly, that $80 \%$ of their patients suffered a significant hearing loss after the procedure. On the other hand, $\mathrm{Hu}$ and Parnes ${ }^{27}$ in 2010, and Teufert and Doherty, ${ }^{28}$ in the same year, stated that cochleosacculotomy gave results comparable with those of endolymphatic sac surgery and other nondestructive procedures performed to suppress vertigo in Ménière's syndrome. In 2015, Soheilipour et $\mathrm{al}^{29}$ revisited this surgical option. They compared 23 patients who underwent cochleosacculotomy with 14 patients who had endolymphatic sac decompression surgery. Vertigo improved significantly in both groups but the hearing level was significantly impacted, especially in patients who had undergone cochleosacculotomy, speaking in favor of endolymphatic sac decompression.

A novel surgical technique for the treatment of Ménière's disease was described recently, the endolymphatic duct blockage. In this technique, the sac is not incised or dissected from the posterior fossa dura. All the bone found around the endolymphatic duct is dissected in order to identify as much of the duct as possible, then the duct is blocked with two small titanium clips. ${ }^{30}$ In 2015 , Saliba et al ${ }^{30}$ reported a nonblinded randomized controlled trial comparing this technique against traditional endolymphatic sac decompression and found that $96.5 \%$ of the patients in the endolymphatic blockage group had achieved a complete control of vertigo spells against $37.5 \%$ of the endolymphatic sac decompression group, with no significant difference between the preoperative and the postoperative hearing levels in both groups. Their study suggested that this novel technique might be better than endolymphatic sac decompression. In a followup study in 2016, with a larger group of patients, this same group reported a total absence of Ménière's attacks in $89.9 \%$ of the patients treated with this novel technique. ${ }^{31}$

The endolymphatic sac surgery keeps evolving, as it seems to be a universally accepted procedure for the treatment of difficult to control Ménière's disease, even though it is still controversial. In a 2014 anatomical study of the temporal bone, Locke et $\mathrm{al}^{32}$ explained that one possible reason for the inconsistent results obtained with endolymphatic sac surgeries is that the sac itself is difficult to identify and a proper decompression is not often accomplished, much less a proper drainage. The reason for this is that the intradural component of the sac varies in size and position.

\section{Discussion}

The senior author has treated more than 90 patients with Ménière's disease with endolymphatic sac decompression since 1984, both in the National Institute of Neurology and Neurosurgery in Mexico City, and also in his private practice. Every patient complied with the criteria established at the 
time by the American Academy of Otolaryngology - Head and Neck Surgery (AAO-HNS). The method of endolymphatic sac decompression and drainage he employs is the same described by Portmann, and later modified by House. ${ }^{7,8,10}$ It starts with a retroauricular C-shaped incision, as performed in retroauricular mastoid approaches, and a wide exposition of the mastoid cortex, a simple mastoidectomy and the proper identification of the posterior and lateral semicircular canals. The latter will serve as a landmark to identify the sac. After that, the bone that covers the sigmoid sinus and the posterior cranial fossa is thinned. Sometimes a small island of bone might be left covering the sigmoid sinus to prevent its damage, and by pressing it, the retrolabyrinthine area is better visualized. The sac is then identified between the posterior semicircular canal and the sigmoid sinus as a white and dense thickening of the dura. After properly identification of the sac, it is then carefully opened and drained. A Teflon (Hood Laboratories, Pembroke, USA) tube may or may not be used to obtain a permanent drainage into the subarachnoid space. Absorbable gelatin sponge saturated in a steroid and antibiotic solution is then placed in the mastoid cavity and the wound is closed in an ordinary fashion.

As we mentioned earlier, some authors have repeatedly suggested that the endolymphatic sac surgery is not more effective than a placebo. ${ }^{4-6}$ Regardless of all uncertainties surrounding Ménière's disease treatment, and based on his experience, the senior author considers endolymphatic sac decompression and drainage as an excellent option to control vertiginous symptomatology and obtain auditory stabilization for medically refractory Ménière's disease with serviceable hearing.

The meta-analysis by Sood et al $^{19}$ showed a vertigo control in the long term, after approximately 3 years of follow-up, of $81.6 \%$ of the patients for sac decompression alone compared to $75.7 \%$ for current mastoid shunt techniques. All in categories $A$ and $\mathrm{B}$ according to the AAO-HNS classification representing total resolution and great improvement of vertigo respectively. ${ }^{33}$ The results we have obtained are very similar.

As we mentioned earlier, a technique called endolymphatic duct blockage was described recently. ${ }^{30,31}$ Great results were obtained by directly blocking the endolymphatic duct with clamps. Physiologically, this is a completely different approach to what surgeons have been doing for years, which is, improving endolymphatic drainage. Undoubtedly, the pathophysiologic basis under which endolymphatic sac surgery works is ill understood and these latter works are a proof of that.

Something worth mentioning is that most of the authors who speak against endolymphatic sac surgery promote chemical labyrinthectomy with aminoglycosides, typically gentamicin. Chia et al $^{34}$ did a meta-analysis in 2014 that included 980 patients from 27 studies where they compared five different delivery methods for gentamicin to access the inner ear. Considering all five groups together, a complete control of vertigo was obtained in $73.6 \%$ of the patients, with a significantly greater vertigo control rate achieved by the titration method (81.7\%). Overall improvement in vertigo was seen in $90.2 \%$ of the patients and an important hearing loss was observed in $25.1 \%$ of patients showing that genta- micin is not safe for hearing preservation considering that 1 in every 4 patients will present hearing loss. The metaanalysis by Sood et $\mathrm{al}^{19}$ shows that with endolymphatic sac decompression alone, postoperative hearing was stable or improved in $72.8 \%$ of patients and when using mastoid shunts (with and without Silastic) postoperative hearing was stable or improved in $71.4 \%$ of them.

Most studies show that employing endolymphatic sac surgery for intractable Ménière's disease has a good chance of achieving complete or substantial control of vertigo for the next couple of years. In an article from 2002, Huang ${ }^{35}$ reported his experience after more than 3000 endolymphatic sac decompression surgeries, where he stated that although it seems unlikely to obtain a short-term rate of vertigo control superior to $90 \%$, there is still room to improve the long-term control of Ménière's disease symptoms, either by modifying the surgical procedure or by employing the treatment at early stages of the disease. Studies with a follow-up longer than 10 years are scarce. In 2016, Bento et $\mathrm{al}^{36}$ reported of 95 patients that underwent endolymphatic sac decompression and drainage with a follow-up period that ranged from 3 to 15 years after surgery (average, 9 years), with 45 patients followed for a period longer than 10 years. In patients with unilateral disease, vertigo control was obtained in $94.3 \%$ of patients. A significant improvement in cochlear function was seen in $14 \%$ of patients, and hearing was preserved or improved in $88 \%$ of them. For the bilateral group, vertigo control was obtained in $85.7 \%$ of the patients and cochlear function improved in $28 \%$ of them. Hearing preservation was attained in $71 \%$ of these patients. It is important to mention that the natural history and progression of endolymphatic hydrops complicates the analysis of long-term surgical results since a large number of patients will ultimately stop having vertigo episodes by the time their posterior labyrinth is completely destroyed and their hearing is lost. ${ }^{37}$

\section{Final Comments}

Endolymphatic sac surgery is still an excellent non-destructive surgical option for patients with incapacitating endolymphatic hydrops. It provides hearing preservation and a high percentage of vertigo control. Even though less surgeons indicate it these days on account of improvements in medical therapies and office-based procedures, it has important advantages over other forms of treatment for medically refractory Ménière's disease.

\section{Conflict of Interest}

The authors declare no conflicts of interest.

\section{References}

1 Snow JB Jr, Kimmelman CP. Assessement of surgical procedures for Ménière's disease. Laryngoscope 1979;89(5 Pt 1):737-747

2 Durland WF Jr, Pyle GM, Connor NP. Endolymphatic sac decompression as a treatment for Meniere's disease. Laryngoscope 2005;115(08):1454-1457 
3 Brinson GM, Chen DA, Arriaga MA. Endolymphatic mastoid shunt versus endolymphatic sac decompression for Ménière's disease. Otolaryngol Head Neck Surg 2007;136(03):415-421

4 Thomsen J, Bretlau P, Tos M, Johnsen NJ. Placebo effect in surgery for Ménière's disease. A double-blind, placebo-controlled study on endolymphatic sac shunt surgery. Arch Otolaryngol 1981; 107(05):271-277

5 Thomsen J, Bretlau P, Tos M, Johnsen NJ. Endolymphatic sacmastoid shunt surgery. A nonspecific treatment modality? Ann Otol Rhinol Laryngol 1986;95(1 Pt 1):32-35

6 Bretlau P, Thomsen J, Tos M, Johnsen NJ. Placebo effect in surgery for Menière's disease: nine-year follow-up. Am J Otol 1989;10(04):259-261

7 Portmann G. The saccus endolinphaticus and the operation for draining the same for relief of vertigo. J Laryngol Otol 1927; 42:809-817

8 Portamann G. Surgical Treatment of vertigo by opening of the saccus endolymphaticus. Arch Otolaryngol 1969;89(06):809-815

9 Hallpike CS, Cairns H. Observation on pathology of Ménière's syndrome. J Laryngol Otol 1938;53:624-654

10 House WF. Subarachnoid shunt for drainage of endolymphatic hydrops. A preliminary report. Laryngoscope 1962;72:713-729

11 Kimura RS. Experimental Blockage of the endolymphatic duct and sac and its effects on the inner ear of the guinea pig. Ann Otol Rhinol Laryngol 1967;76(03):4664-4687

12 Paparella MM, Hanson DG. Endolymphatic sac drainage for intractable vertigo (method and experiences). Laryngoscope 1976; 86(05):697-703

13 Paparella MM, Goycoolea M. Panel of Menière's disease. Endolymphatic sac enhancement surgery for Menière's disease: an extension of conservative therapy. Ann Otol Rhinol Laryngol 1981;90(6 Pt 1):610-615

14 Brown JS. A ten year statistical follow-up of 245 consecutive cases of endolymphatic shunt and decompression with 328 consecutive cases of labyrinthectomy. Laryngoscope 1983;93 (11Pt 1):1419-1424

15 Söderman AC, Ahlner K, Bagger-Sjöbäck D, Bergenius J. Surgical treatment of vertigo-the Karolinska Hospital policy. Am J Otol 1996;17(01):93-98

16 Convert C, Franco-Vidal V, Bebear JP, Darrouzet V. Outcome-based assessment of endolymphatic sac decompression for Ménière's disease using the Ménière's disease outcome questionnaire: a review of 90 patients. Otol Neurotol 2006;27(05):687-696

17 Goto F, Tsutsumi T, Ogawa K. Lateral semicircular canal plugging with endolymphatic sac decompression as new surgical treatment for intractable Meniere's disease. Acta Otolaryngol 2012; 132(08):893-895

18 Kim SH, Ko SH, Ahn SH, Hong JM, Lee WS. Significance of the development of the inner ear third window effect after endolymphatic sac surgery in Ménière disease patients. Laryngoscope 2012;122(08):1838-1843

19 Sood AJ, Lambert PR, Nguyen SA, Meyer TA. Endolymphatic sac surgery for Ménière's disease: a systematic review and metaanalysis. Otol Neurotol 2014;35(06):1033-1045

20 Brookes GB. Circulating immune complexes in Meniere's disease. Arch Otolaryngol Head Neck Surg 1986;112(05):536-540

21 Alleman AM, Dornhoffer JL, Arenberg IK, Walker PD. Demonstration of autoantibodies to the endolymphatic sac in Meniere's disease. Laryngoscope 1997;107(02):211-215
22 Shea JJ Jr. The role of dexamethasone or streptomycin perfusion in the treatment of Meniere's disease. Otolaryngol Clin North Am 1997;30(06):1051-1059

23 Sennaroglu L, Sennaroglu G, Gursel B, Dini FM. Intratympanic dexamethasone, intratympanic gentamicin, and endolymphatic sac surgery for intractable vertigo in Meniere's disease. Otolaryngol Head Neck Surg 2001;125(05):537-543

24 Garduño-Anaya MA, Couthino De Toledo H, Hinojosa-González R, Pane-Pianese C, Ríos-Castañeda LC. Dexamethasone inner ear perfusion by intratympanic injection in unilateral Ménière's disease: a two-year prospective, placebo-controlled, doubleblind, randomized trial. Otolaryngol Head Neck Surg 2005volume>133(02):285-294

25 Kitahara T, Kubo T, Okumura S, Kitahara M. Effects of endolymphatic sac drainage with steroids for intractable Meniere's disease: a long-term follow-up and randomized controlled study. Laryngoscope 2008;118(05):854-861

26 Giddings NA, Shelton C, O'Leary MJ, Brackmann DE. Cochleosacculotomy revisited. Long-term results poorer than expected. Arch Otolaryngol Head Neck Surg 1991; 117(10):1150-1152

$27 \mathrm{Hu}$ A, Parnes LS. 10-year review of endolymphatic sac surgery for intractable meniere disease. J Otolaryngol Head Neck Surg 2010; 39(04):415-421

28 Teufert KB, Doherty J. Endolymphatic sac shunt, labyrinthectomy, and vestibular nerve section in Meniere's disease. Otolaryngol Clin North Am 2010;43(05):1091-1111

29 Soheilipour S, Abtahi SH, Soltani M, Khodadadi HA. Comparison the results of two different vestibular system surgery in patients with persistent Meniere's disease. Adv Biomed Res 2015; 4:198-07

30 Gabra N, Asmar MH, Berbiche D, Saliba I. Endolymphatic duct blockage: quality of life assessment of a novel surgical technique for Ménière disease. Eur Arch Otorhinolaryngol 2016;273(10): 2965-2973; [Epub ahead of print ]

31 Saliba I, Gabra N, Alzahrani M, Berbiche D. Endolymphatic duct blockage: a randomized controlled trial of a novel surgical technique for Ménière's disease treatment. Otolaryngol Head Neck Surg 2015;152(01):122-129

32 Locke RR, Shaw-Dunn J, O'Reilly BF. Endolymphatic sac surgical anatomy and transmastoid decompression of the sac for the management of Ménière's disease. J Laryngol Otol 2014; 128(06):488-493

33 Committee on Hearing and Equilibrium guidelines for the diagnosis and evaluation of therapy in Menière's disease. American Academy of Otolaryngology-Head and Neck Foundation, Inc. Otolaryngol Head Neck Surg 1995;113(03):181-185

34 Chia SH, Gamst AC, Anderson JP, Harris JP. Intratympanic gentamicin therapy for Ménière's disease: a meta-analysis. Otol Neurotol 2004;25(04):544-552

35 Huang TS. Endolymphatic sac surgery for Meniere's disease: experience with over 3000 cases. Otolaryngol Clin North Am 2002;35(03):591-606

36 Bento RF, Cisneros JC, De Oliveira Fonseca AC. Endolymphatic sac drainage for the treatment of Ménière's disease. J Laryngol Otol 2016:1-6 [ Epub ahead of print ]

37 Silverstein H, Smouha E, Jones R. Natural history vs. surgery for Menière's disease. Otolaryngol Head Neck Surg 1989;100(01): 6-16 